\title{
Documento
}

\section{Parecer CFE no 977/65, aprovado em 3 dez. 1965}

\section{Definição dos cursos de pós-graduação}

O sr. ministro da Educação e Cultura, considerando a necessidade de implantar e desenvolver o regime de cursos-pós-graduação em nosso ensino superior e tendo em vista a imprecisão, que reina entre nós, sobre a natureza desses cursos, solicita ao Conselho pronunciamento sobre a matéria que defina e, se for o caso, regulamente os cursos de pós-graduação a que se refere a letra b do art. 69 da Lei de Diretrizes e Bases.

A iniciativa do sr. ministro vem, assim, ao encontro da indicação já apresentada pelo conselheiro Clóvis Salgado no sentido de que fossem devidamente conceituados pelo Conselho os cursos de pós-graduação, especialização, aperfeiçoamento e extensão de que trata o artigo citado. Justificando a indicação alegava o eminente Conselheiro que a definição legal "está um tanto vaga, prestando-se a interpretações discordantes”. Ressalta, ainda, que além da maneira equívoca pela qual as escolas têm definido aqueles cursos nos estatutos e regimentos, o poder público, ao elaborar projetos de auxílios financeiros para o aperfeiçoamento de pessoal de nível superior, "serve-se desse termos deixando certa perplexidade aos administradores e interessados”. Daí concluir que "tanto do ponto de vista escolar, como administrativo, seria louvável uma conceituação mais precisa, de caráter mais operacional que doutrinária”.
Com efeito, o exame dos estatutos e regimentos nos tem mostrado que, de modo geral, falta às escolas uma concepção exata da natureza e fins da pós-graduação, confundindo-se freqüentemente seus cursos com os de simples especialização.

O sr. ministro, que se propõe a desenvolver uma política eficaz de estímulo à realização dos cursos pósgraduados, encarece a definição do Conselho por entender, com razão, que se faz necessário clarear e disciplinar o que "o legislador deixou expresso em forma algo nebulosa”. Aliás, o aviso ministerial não se limita a solicitar uma interpretação, mas ainda indica certos pontos básicos em função dos quais seria disciplinada a pós-graduação. Entende o sr. ministro que esses cursos, destinados à formação de pesquisadores e docentes para os cursos superiores, deveriam fazer-se em dois ciclos sucessivos, "equivalentes ao de master e doctor da sistemática norte-americana”, fixando o Conselho "as exigências mínimas para sua realização e expedição dos respectivos diplomas". Sugere, ainda, que "tais cursos constituam a atribuição das universidades, antes que de estabelecimentos isolados. Quando, em caráter excepcional, o estabelecimento isolado deva realizar curso de pós-graduação, essa iniciativa deverá ficar sujeita à prévia autorização do Conselho".

Como se vê, o que nos propõe o sr. ministro importa não apenas em definir, mas em regulamentar a pós-gra- 
duação. Ora, no regime instituído pela Lei de Diretrizes e Bases, a competência do Conselho para regulamentar cursos superiores estende-se somente àqueles que se enquadram nos termos do art. 70, isto é, os que habilitam à obtenção de diploma capaz de assegurar privilégios para o exercício de profissão liberal. Desde que a lei não distingue, segue-se que tais cursos podem ser de graduação ou pós-graduação. Por enquanto, existe apenas um curso de pós-graduação que satisfaz a essas condições, estando, por isso mesmo, sujeito à regulamentação por parte deste Conselho, que é o curso de orientação educativa.

Nos termos da Lei de Diretrizes e Bases não poderia o Conselho regulamentar os cursos de pós-graduação em geral, condicionando o funcionamento desses cursos à sua prévia autorização ou determinando-lhe a forma e estrutura.

No entanto, com a aprovação do Estatuto do Magistério é possível regulamentar-se a pós-graduação, desde que o art. 25 do Estatuto confere ao Conselho a competência para definir os cursos de pós-graduação e as suas características.

Atendendo à solicitação do sr. ministro e cumprindo desde já a determinação do Estatuto do Magistério, procuraremos neste parecer definir a natureza e objetivos dos cursos de pós-graduação, à luz da doutrina e do texto legal, concluindo por apresentar as suas características fundamentais na forma da exigência legal.

\section{Origem histórica da pós-graduação}

A pós-graduação - o nome e o sistema - tem sua origem próxima na própria estrutura da universidade norte-americana, compreendendo o college como base comum de estudos e as diferentes escolas graduadas que geralmente requerem o título de bacharel como requisito de admissão. Assim, em virtude dessa organização a Universidade acha-se dividida em dois grandes planos que se superpõem hierarquicamente: o undergraduate e o graduate. No primeiro encontra-se os cursos ministrados no college conduzindo ao B.A. e ao B.Sc., e o segundo abrange os cursos pós-graduados, principalmente aqueles que correspondem a estudos avançados das matérias do college visando aos graus de mestre ou doutor. A grande Cyclopedia of Education, editada por Paul Monroe nos começos deste século, definia pós-graduado como termo comum, usado nos Estados Unidos, para designar estudantes que já fizeram o college; ou seja, o estudante pós-graduado é o que possui o grau de bacharel e continua a fazer estudos regulares com vista a um grau superior.

Mas o desenvolvimento sistemático da pós-graduação nos Estados Unidos pode ser considerado como produto da influência germânica e coincide com as grandes transformações da universidade americana nas últimas três décadas do século passado. É quando a universidade deixa de ser uma instituição apenas ensinante e formadora de profissionais para dedicar-se às atividades de pesquisa científica e tecnológica. Na verdade, a pós-graduação adquire seu grande impulso com a fundação da Universidade Johns Hopkins em 1876, criada especialmente para desenvolver estudos pós-graduados e inspirada na idéia da creative scholarship. Isto é, uma universidade destinada não somente à transmissão do saber já constituído, mas voltada para a elaboração de novos conhecimentos mediante a atividade de pesquisa criadora.

Como salienta Walton C. John, em seu livro Graduate Study Universities and Colleges in United States, o movimento pela pós-graduação "representa a culminação da influência germânica no ensino superior norte-americano. A Graduate School é o equivalente da Faculdade de Filosofia da Universidade alemã”. Com efeito, correspondendo os estudos realizados no college americano aos do ginásio alemão em suas classes superiores, somente na pós-graduação seria alcançado o autêntico nível universitário. Característica dessa influência é, por exemplo, o Ph.D., doutor em filosofia, o qual, embora conferido em qualquer setor das ciências ou das letras, é assim chamado porque a primitiva Faculdade das Artes tornou-se, na Alemanha, a Faculdade de Filosofia. Inspirando-se nessa faculdade, a Graduate School, isto é, o instituto que se encarrega dos cursos pós-graduados, será a universidade americana o lugar, por excelência, onde se faz a pesquisa científica, se promove a alta cultura, se forma o scholar, se treinam os docentes dos cursos universitários.

\section{Necessidade da pós-graduação}

Independente dessas origens, o sistema de cursos pós-graduados hoje se impõe e se difunde em todos os países, como a conseqüência natural do extraordinário progresso do saber em todos os setores, tornando impossível proporcionar treinamento completo e adequado para muitas carreiras nos limites dos cursos de graduação. Na verdade, em face do acúmulo de conhecimentos 
em cada ramo das ciências e da crescente especialização das técnicas, o estudante moderno somente poderá obter, ao nível da graduação, os conhecimentos básicos de sua ciência e de sua profissão. Nesse plano, dificilmente se poderia alcançar superior competência nas especializações científicas ou profissionais. A contentarmo-nos com a graduação, teríamos de aumentar a duração dos cursos, o que seria antieconômico e antipedagógico, pois suporia que todos os alunos fossem igualmente aptos e estivessem todos interessados na especialização intensiva e na formação científica avançada. Ou deveríamos multiplicar os cursos graduados para atender ao número cada vez maior de especialidades dentro de uma mesma profissão ou ciência, o que importaria na especialização antecipada em prejuízo de uma preparação básica geral; ou haveríamos de sobrecarregar o currículo, com o resultado de se conseguir formação enciclopédica e superficial. Tudo isso nos mostra que sendo ilusório pretender-se formar no mesmo curso o profissional comum, o cientista e o técnico de alto padrão, e tornando-se cada vez mais inviável a figura do técnico polivalente, temos de recorrer necessariamente aos estudos pós-graduados, seja para completar a formação do pesquisador, seja para o treinamento do especialista altamente qualificado.

Com isto não se pretende diminuir a importância dos cursos de graduação no preparo de profissionais e na formação básica dos pesquisadores. O próprio Conselho, em estudos especiais (Documenta, 3) teve ocasião de acentuar a necessidade de iniciar o estudante na pesquisa científica já ao nível desses cursos. Não se trata, portanto, de transferir, pura e simplesmente, para o âmbito da pós-graduação todo esforço de treinamento científico. Mesmo porque a grande maioria se contenta com a graduação para os seus objetivos profissionais ou na formação cultural. Mas por outro lado seria frustrar as aspirações daqueles que buscam ampliar e aperfeiçoar seus conhecimentos senão lhes proporcionássemos um ciclo mais elevado de estudo onde pudessem ser aproveitados seus talentos e capacidades. Além disso as exigências da formação científica ou tecnológica em grau avançado não poderiam satisfazer-se com os cursos de graduação, como infelizmente parece ser a regra geral na universidade brasileira, ressalvadas as clássicas, mas bem escassas, exceções.

De qualquer modo, o desenvolvimento do saber e das técnicas aconselha introduzir na universidade uma espécie de diversificação vertical com o escalonamento de níveis de estudo que vão desde o ciclo básico, a graduação até a pós-graduação. Haveria desta forma uma infraestrutura correspondente ao plano do ensino, cujo objetivo seria, de um lado a instrução científica e humanista para servir de base a qualquer ramo, e doutra parte teria por fim a formação profissional; e uma superestrutura destinada à pesquisa, cuja meta seria o desenvolvimento da ciência e da cultura em geral, o treinamento de pesquisadores, tecnólogos e profissionais de alto nível.

Sem usar os termos de graduação e pós-graduação o ensino superior francês vem adotando ultimamente o escalonamento em ciclos sucessivos. O primeiro é o mesmo do ano propedêutico e o segundo é o dos anos da licença; é o ciclo clássico. O terceiro ciclo é o do doutorado. Mas, como esclarece o prof. Gilbert Varet comentado as evoluções recentes do ensino superior na França, trata-se de um doutorado novo que se prepara em dois ou três anos, não mais na solitude da pesquisa individual, mas no quadro apropriado de uma instituição nova: o instituto de terceiro ciclo, habilitado a oferecer um doutorado em cada especialidade e permitindo, por certos cursos de nível superior, uma preparação coletiva ao doutorado.

A pós-graduação torna-se, assim, na universidade moderna, cúpula dos estudos, sistema especial de cursos exigido pelas condições da pesquisa científica e pelas necessidades do treinamento avançado. O seu objetivo imediato é, sem dúvida, proporcionar ao estudante aprofundamento do saber que lhe permita alcançar elevado padrão de competência científica ou técnico-profissional, impossível de adquirir no âmbito da graduação. Mas, além destes interesses práticos imediatos, a pós-graduação tem por fim oferecer, dentro da universidade, o ambiente e os recursos adequados para que se realize a livre investigação científica e onde possa afirmar-se a gratuidade criadora das mais altas formas da cultura universitária. A universidade de Princenton, por exemplo, insiste particularmente sobre esse aspecto da pós-graduação proclamando que o desígnio central de uma educação pós-graduada é promover o contínuo amor ao saber. Por todos esses motivos é que se vem atribuindo especial ênfase aos estudos pós-graduados em todos os países, sendo que nos Estados Unidos já se introduziu um ciclo mais avançado, o dos estudos post doctoral.

No que concerne à universidade brasileira, os cursos de pós-graduação, em funcionamento regular, quase não existem. Permanecemos até agora aferrados à crença simplista de que, no mesmo curso de graduação, pode- 
mos formar indiferentemente o profissional comum, o cientista e o tecnólogo. O resultado é que, em muitos setores das ciências e das técnicas, o treinamento avançado de nossos cientistas e especialistas há de ser feito em universidades estrangeiras. Daí a urgência de se promover a implantação sistemática dos cursos pós-graduados a fim de que possamos formar os nossos próprios cientistas e tecnólogos, sobretudo tendo em vista que a expansão da indústria brasileira requer número crescente de profissionais criadores, capazes de desenvolver novas técnicas e processos, e para cuja formação não basta a simples graduação. Em nosso entender um programa eficiente de estudos pós-graduados é condição básica para se conferir à nossa universidade caráter verdadeiramente universitário, para que deixe de ser instituição apenas formadora de profissionais e se transforme em centro criador de ciência e de cultura. Acrescente-se, ainda, que o funcionamento regular dos cursos de pós-graduação constitui imperativo da formação do professor universitário. Uma das grandes falhas de nosso ensino superior está precisamente em que o sistema não dispõe de mecanismos capazes de assegurar a produção de quadros docentes qualificados. Daí, a crescente expansão desse ramo de ensino, nessas últimas décadas, se ter feito com professores improvisados e consequentemente rebaixamento de seus padrões. Por isso mesmo o programa de ampliação das matrículas dos cursos superiores supõe uma política objetiva e eficaz de treinamento adequado do professor universitário. E o instrumento normal desse treinamento são os cursos de pós-graduação.

O aviso ministerial, ao solicitar a regulamentação, aponta, em síntese, os três motivos fundamentais que exigem, de imediato, a instauração de sistema de cursos pós-graduados: 1) formar professorado competente que possa atender à expansão quantitativa do nosso ensino superior garantindo, ao mesmo tempo, a elevação dos atuais níveis de qualidade; 2) estimular o desenvolvimento da pesquisa científica por meio da preparação adequada de pesquisadores; 3) assegurar o treinamento eficaz de técnicos e trabalhadores intelectuais do mais alto padrão para fazer face às necessidades do desenvolvimento nacional em todos os setores.

\section{Conceito de pós-graduação}

Assim concebida a pós-graduação, e reconhecida sua fundamental importância para a formação universitá- ria, vemos que constitui regime especial de cursos cuja natureza devemos precisar.

Em primeiro lugar impõe-se distinguir entre pós-graduação sensu stricto e sensu lato. No segundo sentido a pós-graduação, conforme o próprio nome está a indicar, designa todo e qualquer curso que se segue à graduação. Tais seriam, por exemplo, os cursos de especialização que o médico, nos Estados Unidos, deve freqüentar a fim de poder exercer uma especialidade da medicina. Embora pressupondo a graduação esses e outros cursos de especialização, necessariamente, não definem o campo da pós-graduação sensu stricto.

Normalmente os cursos de especialização e aperfeiçoamento tem objetivo técnico-profissional específico sem abranger o campo total do saber em que se insere a especialidade. São cursos destinados ao treinamento nas partes de que se compõe um ramo profissional ou científico. Sua meta, como assinala o conselheiro Clóvis Salgado em sua indicação, é o domínio científico e técnico de uma certa e limitada área do saber ou da profissão, para formar o profissional especializado.

Mas, a distinção importante está em que especialização e aperfeiçoamento qualificam a natureza e destinação específica de um curso, enquanto a pós-graduação, em sentido restrito, define o sistema de cursos que se superpõe à graduação com objetivos mais amplos e aprofundados de formação científica ou cultural. Cursos pós-graduados de especialização ou aperfeiçoamento podem ser eventuais, ao passo que a pós-graduação em sentido próprio é parte integrante do complexo universitário, necessária à realização de fins essenciais da universidade. Não se compreenderia, por exemplo, a existência da universidade americana sem o regime normal de cursos pós-graduados, sem a Graduate School, como não se compreenderia universidade européia sem o programa de doutoramento.

Certamente a pós-graduação pode implicar especialização e operar no setor técnico profissional. Mas neste caso a especialização é sempre estudada no contexto de uma área completa de conhecimentos e quando se trata do profissional o fim em vista é dar ampla fundamentação científica à aplicação de uma técnica ou ao exercício de uma profissão.

Existe, ainda, outra característica não menos importante. Se, em certos casos, a especialização pode ter caráter regular e permanente, como sucede no campo da medicina, seus cursos apenas oferecem certificado de eficiência ou aproveitamento que habilita ao exercício de 
uma especialidade profissional, e que poderão ser obtidos até mesmo em instituições não universitárias, ao passo que a pós-graduação sensu stricto confere grau acadêmico, que deverá ser atestado de uma alta competência científica em determinado ramo do conhecimento, sinal de uma autêntica scholarship.

Em resumo, a pós-graduação sensu stricto apresenta as seguintes características fundamentais: é de natureza acadêmica e de pesquisa e mesmo atuando em setores profissionais tem objetivo essencialmente científico, enquanto a especialização, via de regra, tem sentido eminentemente prático-profissional; confere grau acadêmico e a especialização concede certificado; finalmente a pós-graduação possui uma sistemática formando estrato essencial e superior na hierarquia dos cursos que constituem o complexo universitário. Isto nos permite apresentar o seguinte conceito de pós-graduação sensu stricto: o ciclo de cursos regulares em segmento à graduação, sistematicamente organizados, visando desenvolver e aprofundar a formação adquirida no âmbito da graduação e conduzindo à obtenção de grau acadêmico.

\section{Um exemplo de pós-graduação: a norte-americana}

Sendo, ainda, incipiente a nossa experiência em matéria de pós-graduação, teremos de recorrer inevitavelmente a modelos estrangeiros para criar nosso próprio sistema. O importante é que o modelo não seja objeto de pura cópia, mas sirva apenas de orientação. Atendendo ao que nos foi sugerido pelo aviso ministerial, tomaremos como objeto de análise a pós-graduação norte-americana, cuja sistemática já provada por uma longa experiência tem servido de inspiração a outros países. Vale assinalar que na Inglaterra, recentemente, o já famoso Robbins Report, que estudou as condições de expansão e aperfeiçoamento do ensino superior britânico, não hesitou em recomendar às universidades britânicas o uso de certas técnicas e processos da pós-graduação norteamericana.

Nos Estados Unidos a pós-graduação constitui o sistema de cursos que se seguem ao bacharelado conferido pelo college, normalmente coordenados pela Escola de Pós-Graduação (Graduate School ou Graduate Faculty, como é designada pela Universidade de Columbia) e com o poder de conferir os graus de mestre (M.A. ou M.S.) e de doutor (Ph.D., Philosophiae Doctor).

Mestrado e doutorado. Mestrado e doutorado re- presentam dois níveis de estudos que se hierarquizam. Distinguem-se o doutorado de pesquisas, o Ph.D. que é o mais importante dos graus acadêmicos conferidos pela universidade norte-americana, e os doutorados profissionais, como por exemplo, doutor em ciências médicas, doutor em engenharia, doutor em educação etc. O mestrado tanto pode ser de pesquisa como profissional. O tipo mais comum é o Mestre das Artes (Master of Arts), expressão que é uma sobrevivência medieval, onde artes designava as matérias constitutivas do trivium ao quadrivium, isto é, as disciplinas literárias e científicas, conteúdo da Faculdade das Artes.

Embora hierarquizados, são dois graus relativamente autônomos, isto é, o Ph.D. não exige necessariamente o M.A. como requisito indispensável. Existe universidade, como a de Princeton, cuja Graduate School opera quase que exclusivamente com programa de doutorado. Em certas profissões, como a de medicina, não se verifica o mestrado, nesse ponto diferente da Inglaterra onde ocorre o mestrado em cirurgia. Numa mesma universidade há departamentos que não trabalham com programas de mestrado. Na Graduate Faculty da Universidade de Columbia, por exemplo, existe o doutorado em anatomia, bioquímica, farmacologia, patologia, fisiologia, microbiologia, todas como se vê, matérias do ciclo básico de medicina.

O título de mestre, peculiar às universidades americanas e britânicas, tem sua origem como grau acadêmico na universidade medieval. Com efeito, na Idade Média chamavam-se mestres todos os licenciados que faziam parte da corporação dos professores em todas as faculdades, com exceção da Faculdade de Direito (decreto ou civil) onde os professores se intitulavam doutores. $\mathrm{O}$ licenciado adquiria o título de mestre no ato solene da inceptio, pelo qual era recebido na corporação dos mestres com todos os direitos e privilégios. Na verdade, segundo nos diz Rashdall em seu livro The Universities of Europe in the Middle Ages, vol. I, na universidade medieval os três títulos, mestre, doutor e professor eram absolutamente sinônimos. Para o fim da Idade Média os professores das faculdades, ditas superiores, tenderam a assumir o título de doutor em substituição ao de mestre, ficando este para a Faculdade das Artes.

Após o Renascimento, com as transformações sofridas pela universidade, o grau de mestre tende a desaparecer nas instituições européias, sendo conservado até hoje no mundo anglo-saxônico. Em Oxford e Cambridge o grau de Mestre das Artes é concedido sem 
qualquer exame a todo aquele que haja obtido o grau de bacharel numa destas universidades e tenha seu nome nos livros de uma sociedade (isto é, tenha pago as taxas correspondentes da universidade ou de um colégio) por um prazo de vinte e um períodos de estudos. Nas universidade escocesas o M.A. é o grau concedido ao término do curso de graduação. Nos Estados Unidos, por força da influência inglesa permaneceu o grau de mestre, sendo, por muito tempo, conferido sem maiores exigências no fim da graduação, como era o caso do chamado Masters Degree in cursu. Pelos fins do século passado, com a instituição do doutorado segundo o modelo germânico, foi reformulado o M.A., para obtenção do qual se exigem cursos e exames, tornando-se ele um grau inferior ao Ph.D.

Ultimamente, segundo acentua Walter S. Eells no seu livro Degrees in Highes Education, muito se tem discutido sobre a significação e valor do mestrado. Os relatórios das Associações de Escolas de Pós-Graduação têm se ocupado do problema recomendando a revitalização do grau de mestre. Discute-se por exemplo, se o M.A. é um grau final, com autonomia funcional ou apenas uma etapa no caminho para o Ph.D.; se é importante apenas para a formação do professor do ensino secundário ou também para o professor do college; se deve exigir-se para o mestrado uma tese e ser aumentada sua duração.

O mestrado adquire significação própria como grau terminal para aqueles que desejando aprofundar a formação científica ou profissional recebida nos cursos de graduação, não possuem vocação ou capacidade para a atividade de pesquisa que o Ph.D. deve ser o atestado. Assim, em Johns Hopkins, no Departamento de Física, embora ordinariamente sejam aceitos apenas candidatos ao doutorado, admite-se mudança de programa para o M.A. se, por qualquer razão, o estudante se julga incapaz de completar os estudos necessários ao Ph.D. Nos Estados Unidos o grau de mestre é de grande utilidade como sinal de competência profissional, a exemplo do que ocorre com o mestrado em engenharia, arquitetura ou ciências da administração pública ou de empresas. É importante igualmente para o magistério secundário, sobretudo porque em muitos estados o mestrado é garantia de melhor remuneração. No ensino superior é de menor valia, pois o Ph.D. é título necessário para o acesso na carreira de professor universitário. Dificilmente se poderia atingir o posto de professor associado e, muito menos, de professor sem o doutorado. De qualquer modo o mestrado se justifica como grau autônomo por ser um nível da pós-graduação que proporciona maior competência científica ou profissional para aqueles que não desejam ou não podem dedicar-se à carreira científica.

Duração de cursos e métodos empregados. O doutorado norte-americano representa muito mais que a defesa de uma tese. Doutorado e mestrado são o resultado de estudos regulares e rigorosos em determinado campo do saber podendo prolongar-se por tempo maior do que o necessário à graduação. Teoricamente se requer um ano para o M.A. e dois anos para o Ph.D. Na realidade essa duração principalmente no caso do doutorado, pode estender-se por vários anos conforme a capacidade do aluno e a natureza da matéria. Em geral exige-se um ano acadêmico de residência para ambos os graus. Por este ano de residência entende-se a freqüência regular aos cursos pós-graduados com a obtenção dos respectivos créditos. Muitas vezes determina-se o limite máximo de duração dos estudos. Assim, a Universidade de Columbia exige que o candidato apresente a tese de doutorado dentro do prazo de sete anos, admitindo-se exceções em circunstâncias especiais quando recomendadas pelo departamento.

Estudo publicado em 1951 revelou que, de 20.000 candidatos que obtiveram o Ph.D. em ciências de 1936 a 1948, o tempo médio decorrido entre o bacharelado e o grau de doutor foi de 6,2 anos, com a metade dos graduados dispendendo de 5 a 6 anos cada um. A média de idade em que receberam o grau foi de 30,5 anos, variando de 19 a 65 anos.

Em geral, segundo esclarece Walter C. Eells, após o candidato ao Ph.D. haver completado dois anos de estudo em residência e escolhido o tema da tese, por motivos econômicos abandona o tempo integral, freqüentando cursos de verão ou períodos irregulares até a conclusão de tese.

Quanto à maneira de se processarem os cursos, aos métodos de instrução e às condições estabelecidas para a obtenção do grau, notam-se sensíveis variações de universidade para universidade e, até mesmo, de departamento para departamento na mesma instituição. Todavia, apesar de grande diversidade de métodos e requisitos é possível falar-se de uma sistemática comum. Característica fundamental da pós-graduação norte-americana é que o candidato ao mestrado e ao doutorado, além da tese, dissertação ou ensaio, deverá seguir certo número de cursos, participar de seminários e trabalhos de pesquisas, e submeter-se a uma série de exames, incluindo-se as provas de língua estrangeira. 
Entende-se, por outro lado, que a pós-graduação, por sua natureza, implica rigorosa seletividade intelectual, estabelecendo-se requisitos de admissão tanto mais severos quanto mais alto é o padrão da universidade. E, uma vez admitido, o candidato enfrentará rigorosos exames eliminatórios, exigindo-se dele intenso trabalho intelectual ao longo do curso. Como faz questão de acentuar a universidade John Hopkins, a pós-graduação de modo algum pode ser considerada educação de massa. Daí a filtragem dos candidatos. A Universidade de Princeton, por exemplo, dos dois mil pedidos de inscrição que lhe chegam anualmente, não aproveita mais do que trezentos e cinqüenta.

Normalmente os cursos de mestrado e doutorado compreendem uma área de concentração (major) à escolha do candidato e matérias conexa (minor). No caso do Ph.D. a exigência da tese é universal, enquanto para o M.A. ora se requer uma dissertação, memória ou ensaio, ora se consideram suficientes os exames prestados.

Os processos de aprendizagem se caracterizam pela grande flexibilidade atribuindo-se ao candidato larga margem de liberdade na seleção dos cursos embora assistidos e orientados por um diretor de estudos. São utilizados de preferência métodos, tais como seminários, programas de pesquisa, trabalhos de laboratórios etc., que visem estimular a iniciativa criadora do aluno. O método de instrução, por excelência, nestes cursos, principalmente na área das humanidades e ciências sociais, é o seminário. O propósito dos seminários, considerados coletivamente, é investigar um determinado tópico, combinando amplitude e profundidade e possibilitando ao aluno participação ativa no desenvolvimento dos temas. De qualquer modo, o que se tem em vista nos cursos de pós-graduação é menos fazer o candidato absorver passivamente conhecimentos já feitos, do que desenvolver sua capacidade criadora e juízo crítico, levando-o a exercer, por si mesmo ou em colaboração com mestre, a atividade de pesquisa.

Para melhor ilustração, usaremos de um exemplo tirado de nossa especialidade descrevendo, em suas linhas gerais, os requisitos necessários ao M.A. e Ph.D. em filosofia, na Universidade de Chicago. Aliás, nesta universidade o estudante tem a escolha entre dois M.A. de filosofia: um M.A. especializado, para aquele que tem a intenção de dedicar-se à filosofia e projeta preparar, em seguida, o doutorado; e um M.A. de caráter geral destinado principalmente aos candidatos que tem o propósito de aplicar os seus conhecimentos filosóficos a domínio e problemas outros que os da filosofia propriamente dita.
Para obter o M.A. especializado em filosofia o aluno deve submeter-se a três exames, aos quais se acrescenta a prova de língua estrangeira: a) um exame preliminar eliminatório sobre quatro domínios da filosofia, indicados pelo departamento; b) um grande exame sobre o domínio de opção; c) um exame sobre campo conexo estranho à filosofia. No que se refere ao Ph.D., o candidato, além das provas que verifiquem sua competência de leitura em duas línguas estrangeiras, deve submeter-se a: a) um exame preliminar obrigatório escrito sobre quatro domínios da filosofia estabelecidos pelo departamento, assim como sobre a obra de um filósofo escolhido pelo candidato de acordo com o seu diretor de estudos; b) um grande exame (comprehensive examination) em três partes: prova escrita sobre a especialidade de opção, prova oral sobre a história da filosofia e prova escrita sobre o domínio conexo; c) um exame oral final sobre o assunto de que trata a tese de doutorado e o campo em que se situa. Para o M.A. especializado exige-se dissertação que demonstre aptidão para a pesquisa; para o M.A. geral basta um ensaio "organizando e interpretando dados relativos a um problema geral”. Quanto ao Ph.D. é necessário o preparo de tese que constitui "contribuição de conhecimentos novos sobre um tema aprovado pelo Departamento".

De certo que esses requisitos e métodos de estudo variam em maior ou menor medida entre os departamentos afim de atender, principalmente, às peculiaridades de cada ramo de conhecimentos. Todavia, apesar da diversidade de processos, existe uma sistemática da pós-graduação norte-americana que compreende, em sua essência, duração mínima de residência, cursos regulares, exames parciais e gerais, incluindo línguas estrangeiras, além da tese, quando se trata do Ph.D., resultado de pesquisa e devendo apresentar contribuição nova para o saber.

O mérito do sistema, especialmente reconhecido pelo Robins Report, está em que a pós-graduação não se limita apenas ao preparo de uma tese doutoral ou uma dissertação de mestrado. Compreende uma série de cursos a que está obrigado o aluno, cobrindo ampla extensão do campo de conhecimento escolhido. Trata-se, portanto, de treinamento intensivo com o objetivo de proporcionar sólida formação científica, encaminhando-se o candidato ao trabalho de pesquisa de que a tese será a expressão. Essa organização sistemática da pós-graduação tem ainda a vantagem de oferecer o máximo de assistência e orientação ao aluno em seus estudos, sem prejuízo de liberdade de iniciativa que lhe é essencial. 


\section{A pós-graduação na Lei de Diretrizes e Bases}

Admitida a doutrina da pós-graduação cujos princípios apenas delineamos, passemos agora ao estudo do problema à luz da Lei de Diretrizes e Bases.

Se considerarmos o destaque especial que a lei concede à pós-graduação ao classificar os diferentes tipos de cursos superiores, podemos afirmar que a doutrina aqui exposta corresponde à intenção do texto legal. É o que pretendemos mostrar com a análise do art. 69 onde se distingue três grandes categorias de cursos:

a) de graduação, abertos à matricula de candidatos que hajam concluído o ciclo colegial ou equivalente, e obtido classificação em concurso de habilitação;

b) de pós-graduação, abertos à matrícula de candidatos que hajam concluído o curso de graduação e obtido o respectivo diploma;

c) de especialização, aperfeiçoamento e extensão, ou quaisquer outros, a juízo do respectivo instituto de ensino abertos a candidatos com o preparo e os requisitos que vierem a ser exigidos.

O dispositivo legal, como se vê, não chega a determinar a natureza da pós-graduação. Se por um lado, essa indefinição, que corresponde ao próprio espírito da lei, representa fator positivo ao dar margem à iniciativa criadora das universidades, doutra parte tem gerado certa confusão, por nos faltar tradição e experiência na matéria. Daí a necessidade de uma interpretação oficial capaz de definir a natureza da pós-graduação a que se refere a letra b do art. 69 e que sirva de balizamento para a organização dos cursos pós-graduados. A exegese do artigo poderá discernir elementos básicos que nos permitem determinar o conceito legal.

Em primeiro lugar, destaca-se o fato importante de que a pós-graduação é mencionada em alínea especial, como categoria própria, a maneira de espécie de que o gênero é o curso. Existe assim uma diferença específica entre a pós-graduação e os cursos de especialização e aperfeiçoamento. Isto nos autoriza a pensar que a lei considerou a pós-graduação sensu stricto tal como a definimos nesse trabalho.

Em segundo lugar, corroborando essa interpretação, é significativo que a lei estabelece expressamente requisito de matrícula para os cursos de pós-graduação, deixando os de especialização, aperfeiçoamento e extensão ao critério dos estabelecimentos. Assim como a conclusão do ciclo colegial ou equivalente é o requisito indispensável à matricula nos cursos de graduação, o diploma destes últimos é requisito imprescindível para a matrícula em cursos pós-graduados. E desde que a lei não exige diploma de graduação para os cursos da alínea c, segue-se que nem toda especialização é necessariamente curso pós-graduado. É possível, por exemplo, pensar-se numa especialização de nível superior para técnicos de grau médio. Por outro lado, ainda que a especialização pressuponha expressamente o diploma de graduação ela não constitui, só por isso, pós-graduação em sentido estrito.

Outro ponto digno de nota é que a lei ao tratar de cursos de graduação e pós-graduação fala de matrícula, usando para ambos os casos da mesma expressão: "abertos (os cursos) à matrícula de candidatos que hajam concluído...”. Com referência aos cursos da alínea c limita-se a dizer simplesmente: "abertos a candidatos...", omitindo a palavra matrícula. Não se pode considerar essa omissão como fortuita e, portanto, irrelevante. Com efeito, o fato de figurar a palavra matrícula toda vez que o artigo se refere aos cursos de graduação e pós-graduação e omitindo nos casos dos cursos da alínea c, para os quais não se exige qualquer requisito, denota uma intenção especial da lei. Como bem ressaltou o conselheiro Clóvis Salgado em sua indicação, quando a lei fala da matrícula para pós-graduação dá a entender que se trata de cursos regulares. Vê-se desse modo que a lei estabelece uma certa paridade, quanto ao caráter sistemático dos cursos, entre a graduação e a pós-graduação. Poderia observar-se que não requer, além do diploma de graduação, nenhuma prova de habilitação aos cursos pós-graduados. Mas daí não se infere que os estabelecimentos fiquem impedidos de fixar critérios de seleção pois, segundo foi visto, a pós-graduação por sua própria natureza implica alta seletividade intelectual. Muito acertadamente deixou a lei que as escolas, conforme os casos concretos, decidissem da conveniência e da forma de seleção.

Desta breve análise do art. 69 podemos concluir, com fundamento, que a intenção da lei foi atribuir status especial à pós-graduação, distinguindo-a dos cursos de simples especialização. Se esta interpretação é exata parece-nos legítimo aplicar-se aos cursos de que trata a alínea b o conceito que formulamos de pós-graduação sensu stricto, isto é, o sistema de cursos regulares que se superpõe à graduação, visando desenvolver, em ampli- 
tude e profundidade, os estudos feitos nos cursos de graduação e conduzido à obtenção de grau acadêmico.

Mas, se o Conselho, interpretando a lei no uso de suas atribuições, pode definir oficialmente a pós-graduação, faltar-lhe-ia, por enquanto, competência como já acentuamos de início, para fazer a regulamentação geral dos cursos pós-graduados. Somente cabe-lhe regulamentar o curso de pós-graduação capaz de assegurar privilégio para o exercício de profissão liberal, nos termos do art. 70. Isto significa que, no atual regime da Lei de Diretrizes e Bases, qualquer estabelecimento, universidade ou faculdade isolada, poderia instalar cursos de pós-graduação conferindo grau, na forma da definição proposta pelo Conselho, mas sem depender, para isso, da autorização ou reconhecimento. Tal é a situação dos cursos pósgraduados na Lei de Diretrizes e Bases.

\section{A pós-graduação e o estatuto do magistério}

Com a promulgação do Estatuto do Magistério, o Conselho dispõe, agora, de poderes para submeter os cursos pós-graduados a uma certa regulamentação.

É certo que o Estatuto não confere privilégio a esses cursos para o exercício do magistério. Ora, sem conferir privilégio não seria o caso de invocar o art. 70 da LDB para submeter os cursos pós-graduados à regulamentação. Todavia, entendemos que a competência atribuída ao Conselho para definir esses cursos e determinar-lhes as características, outorga-lhe, ao mesmo tempo, certo poder para regulamentá-los. Doutra forma como o Conselho poderia ter segurança de que os estabelecimentos seguem as características fixadas? O controle dos cursos poderá ser feito por meio de reconhecimento, pelo menos à maneira de acreditation. $\mathrm{O}$ reconhecimento, ou qualquer outro meio de controle que venha disciplinar o processo de implantação dos cursos de pós-graduação, parece-nos de todo indispensável se considerarmos as condições de funcionamento de nossas escolas superiores. A ser criada indiscriminadamente, a pós-graduação, na maioria dos casos, se limitará a repetir a graduação, já de si precária, com o abastardamento inevitável dos graus de mestre e doutor.

O simples fato de que um estabelecimento tenha seus cursos de graduação reconhecidos não significa que se encontra realmente habilitado para instituir a pósgraduação. Por isso mesmo, se quisermos evitar que a pós-graduação brasileira - essencial à renovação de nossa universidade - seja aviltada em seu nascedouro, de- vemos estabelecer não somente princípios doutrinários mas critérios operacionais e normas que dirijam e controlem sua implantação e desenvolvimento. Daí a necessidade de que os cursos de pós-graduação sejam reconhecidos pelo Conselho.

Propõe o sr. ministro que a pós-graduação seja prerrogativa das universidades e que apenas em condições excepcionais venha a ser permitida aos estabelecimentos isolados mediante autorização do Conselho. Considerada a proposta do ponto de vista legal, verifica-se que tanto na Lei de Diretrizes e Bases como no Estatuto do Magistério nenhum dispositivo existe que autoriza restringir a pós-graduação às universidades. O caput do art. 69 é bastante claro quando dispõe que podem ser ministrados nos estabelecimentos de ensino superior os cursos por ele discriminados, isto é, de graduação, pósgraduação etc.

Por outro lado, se é verdade que em muitos setores da pesquisa científica somente a universidade possui recursos, em pessoal e equipamento, para desenvolver com eficiência programas de pós-graduação, noutras áreas é perfeitamente admissível que uma faculdade isolada possa manter cursos pós-graduados. A faculdade de filosofia, por exemplo, que abrange todos os setores da ciências e das letras, e que operando com todos os seus cursos é uma espécie de universidade, estaria teoricamente em condições de atuar satisfatoriamente no campo da pós-graduação. E se submetermos os cursos pósgraduados ao reconhecimento do Conselho poderá ele fixar normas para o funcionamento desses cursos, cabendo verificar em cada caso se o estabelecimento, universidade ou faculdade isolada, apresenta as condições exigidas.

\section{Definição e características do mestrado e doutorado}

Cabe-nos agora, atendendo à solicitação do sr. ministro e, ao que determina o Estatuto do Magistério, definir e fixar as características dos cursos de mestrado e doutorado.

Entendemos que se trata de caracterizar estes cursos em seus aspectos fundamentais, evitando-se estabelecer padrões rígidos que viessem prejudicar a flexibilidade essencial à toda pós-graduação. Daríamos apenas as balizas mestras dentro das quais a estruturação dos cursos pode sofrer variações em função das peculiaridades de cada setor de conhecimento e da margem de ini- 
ciativa que se deve atribuir à instituição e ao próprio aluno na organização de seus estudos.

Em primeiro lugar, de acordo com a doutrina exposta nesse parecer, propomos o escalonamento da pós-graduação em dois níveis: mestrado e doutorado, não obstante certas objeções, surgidas, entre nós, contra o título de mestre. A alegação, tantas vezes invocada, de que esse título não faz parte de nossa tradição de ensino superior não nos parece constituir razão suficiente para ser rejeitado. A verdade é que em matéria de pós-graduação ainda estamos por criar uma tradição. E, se a pósgraduação deve ser estruturada em dois ciclos, como a experiência anglo-americana demonstra e a própria natureza desses estudos aconselha não vemos porque teríamos escrúpulo em adotar a designação de mestre se, como bem acentuou o conselheiro Rubens Maciel não dispomos de outro nome que a substitua. Aliás, algumas de nossas instituições já vem adotando, com êxito, o título de mestre para designar o grau acadêmico correspondente ao primeiro nível da pós-graduação.

Seguindo-se o critério de maior flexibilidade, em vez de duração uniforme e invariável julgamos mais adequado fixar duração mínima em termos de ano letivo. Com base na experiência estrangeira podemos determinar o mínimo de um ano para o mestrado e dois para o doutorado. O programa de estudos compreenderá um elenco variado de matérias a fim de que o aluno possa exercer opção, orientado pelo diretor de estudos.

Em sua área de concentração, o candidato escolherá certo número de matérias, complementada por outra ou outras escolhidas em campo conexo. O total de estudos exigidos para completar o curso poderá ser avaliado em créditos ou unidades equivalentes. Sistema, que aliás, já vem sendo adotado no curso de mestrado mantido pelo Instituto de Química da Universidade do Brasil. Neste curso requer-se um mínimo de 30 créditos, correspondendo o crédito a cada 17 horas de aulas teóricas ou equivalentes. Por não existir ainda unidade de crédito convencionada para nosso ensino superior deixamos de empregar esse critério de avaliação. Mas, considerandose que na pós-graduação se há de conceder ao aluno certa margem de tempo para os seus estudos e trabalhos de pesquisas individuais, calculamos que seria suficiente, para o mestrado e doutorado, o total de 360 a 450 horas de trabalhos escolares, aulas, seminários ou atividades de laboratórios, por ano letivo.

O programa de estudo comportará duas fases. A primeira fase compreende principalmente a frequêencia às aulas, seminários culminando com um exame geral que verifique o aproveitamento e a capacidade do candidato. No segundo período o aluno se dedicará mais à investigação de um tópico especial da matéria de opção, preparando a dissertação ou tese que exprimirá o resultado de suas pesquisas.

Embora o mestrado e o doutorado represente um escalonamento da pós-graduação, esses cursos podem ser considerados como relativamente autônomos. Isto é, o mestrado não constitui obrigatoriamente requisito prévio para inscrição no curso de doutorado. É admissível que em certos campos do saber ou da profissão se ofereçam apenas programas de doutorado. De qualquer modo, seguindo tradição generalizada em todos os países, não se aconselharia a instituição do mestrado em medicina.

Outro ponto importante é a determinação dos tipos de doutorado e respectiva designação, recomendando-se certa sistemática e uniformidade dos graus. É comum se distinguirem os graus acadêmicos ou de pesquisa e os graus profissionais. Nos Estados Unidos, conforme vimos, o doutorado de pesquisa é o Ph.D., ou seja, Philisophiae Doctor, segundo o modelo germânico e que se aplica a qualquer setor de conhecimento. Assim temos o Ph.D. em física, sociologia, letras, biologia etc. ou em filosofia propriamente dita. Na França cobrindo toda área das ciências e humanidades, temos o Docteur ès Sciences e o Docteur ès Lettres equivalendo às matérias estudadas, respectivamente, na Faculté des Sciencies e na Faculté des Lettres (hoje Faculté des Lettres et Sciencies Humaines). Na Alemanha, além do Dr. Philosophiae relativo às diversas seções da faculdade de filosofia, existe o Dr. Rerum Naturalium, que abrange o campo das ciências naturais ou exatas, o Dr. Rerum Politicarum, que compreende o campo das ciências sociais e econômicas, além dos diversos doutorados relativos às profissões liberais tradicionais.

Se atendermos a que a nossa faculdade de filosofia cobre todo o campo das ciências e das letras e tem como um de seus objetivos essenciais a formação de pesquisadores, poderíamos adotar a expressão Ph.D. para designar o doutorado de pesquisa. Neste caso entende-se que a pós-graduação de pesquisas ou acadêmica seria objeto de uma coordenação central incluindo as disciplinas científicas ou literárias do ciclo básico das faculdades profissionais. Os problemas intrincados e insolúveis de classificação dos diferentes tipos de conhecimento aconselhariam a solução cômoda do Ph.D. Considerando-se, todavia, que esse título não teria ressonância em 
nosso ambiente universitário, havendo já universidades como a de São Paulo, onde se concede regularmente o doutorado em ciências, é preferível não adotar o Ph.D. A dicotomia doutor em ciências e doutor em letras suscita várias dificuldades quanto à inclusão de certas matérias em qualquer uma dessas categorias, desde que não possuímos a tradição francesa das duas faculdades de ciências e de letras. Poderíamos acrescentar um terceiro campo, o das ciências humanas, que também não estaria ao abrigo de toda objeção em matéria de classificação das ciências. Como é possível lograr-se uma classificação sistemática livre de qualquer objeção sugerimos que o doutorado seja articulado com as quatro grandes áreas seguintes: letras, ciências naturais, ciências humanas e filosofia. Quanto aos doutorados profissionais, teriam a designação do curso correspondente como, por exemplo, doutor em engenharia, doutor em medicina etc.

No que concerne ao mestrado deparam-se-nos idênticas dificuldades. Seria de todo inconveniente adotar a expressão Mestre das Artes (M.A.) uma vez que o termo artes perdeu, entre nós, a significação primitiva de artes liberais, isto é, o conjunto das disciplinas científicas e literárias que formavam o conteúdo da Faculdade das Artes da Universidade Medieval. Justifica-se o uso da expressão nos Estados Unidos e na Inglaterra porque ainda hoje, nestes países, se conserva a denominação, de origem medieval, de Colégio das Artes Liberais e Faculdades das Artes. Para evitar maiores complicações propomos que o mestrado seja qualificado pela denominação do curso, área ou matéria correspondente.

A luz da doutrina aqui exposta sobre a natureza e processos da pós-graduação, podemos formular as seguintes conclusões sobre as características fundamentais dos cursos pós-graduados correspondentes aos dois níveis:

1) A pós-graduação de que trata a alínea b do art. 69 da Lei de Diretrizes e Bases é constituída pelo ciclo de cursos regulares em seguimento à graduação e que visam a desenvolver e aprofundar a formação adquirida nos cursos de graduação e conduzem à obtenção de grau acadêmico.

2) A pós-graduação compreenderá dois níveis de formação: mestrado e doutorado. Embora hierarquizados, o mestrado não constitui condição indispensável à inscrição no curso de doutorado.

3) O mestrado pode ser encarado como etapa preliminar na obtenção do grau de doutor ou como grau terminal.
4) O doutorado tem por fim proporcionar formação científica ou cultural ampla e aprofundada, desenvolvendo a capacidade de pesquisa e poder criados nos diferentes ramos do saber.

5) O doutorado de pesquisa terá a designação das seguintes áreas: letras, ciências naturais, ciências humanas e filosofia; os doutorados profissionais se denominam segundo os cursos de graduação correspondentes. O mestrado será qualificado pelo curso de graduação, área ou matéria a que se refere.

6) Os cursos de mestrado e doutorado devem ter a duração mínima de um e dois anos respectivamente. Além do preparo da dissertação ou tese, o candidato deverá estudar certo número de matérias relativas à sua área de concentração e ao domínio conexo, submeter-se a exames parciais e gerais, e provas que verifiquem a capacidade de leitura em línguas estrangeiras. Pelo menos uma para o mestrado e duas para o doutorado.

7) Por área de concentração entende-se o campo específico de conhecimento que constituirá o objeto de estudos escolhido pelo candidato, e por domínio conexo qualquer matéria não pertencente àquele campo, mas considerada conveniente ou necessária para completar sua formação.

8) O estabelecimento deve oferecer um elenco variado de matérias a fim de que o candidato possa exercer sua opção. As matérias, de preferência, serão ministradas sob a forma de cursos monográficos dos quais, seja em preleções, seja em seminários, o professor desenvolverá, em profundidade, um assunto determinado.

9) Do candidato ao mestrado exige-se dissertação, sobre a qual será examinado, em que revele domínio do tema escolhido e capacidade de sistematização; para o grau de doutor requer-se defesa de tese que represente trabalho de pesquisa importando em real contribuição para o conhecimento do tema.

10) O programa de estudos do mestrado e doutorado se caracterizará por grande flexibilidade, deixandose ampla liberdade de iniciativa ao candidato que receberá assistência e orientação de um diretor de estudos. constará o programa, sobretudo, de seminários, trabalhos de pesquisa, atividades de laboratório com a participação ativa dos alunos.

11) O mesmo curso de pós-graduação poderá receber diplomados provenientes de cursos de graduação diversos, desde que apresentem certa afinidade. 
Assim, por exemplo, ao mestrado ou doutorado em administração pública poderiam ser admitidos bacharéis em direito ou economia; em biologia, médicos ou diplomados em história natural.

12) Para matrícula nos cursos de pós-graduação, além do diploma do curso de graduação exigido por lei, as instituições poderão estabelecer requisitos que assegurem rigorosa seleção intelectual dos candidatos. Se os cursos de graduação devem ser abertos ao maior número, por sua natureza, a pósgraduação há de ser restrita aos mais aptos.

13) Nas universidades a pós-graduação de pesquisa ou acadêmica deve ser objeto de coordenação central, abrangendo toda área das ciências e das letras, inclusive das que fazem parte do ciclo básico das faculdades profissionais.

14) Conforme o caso, aos candidatos ao doutorado serão confiadas tarefas docentes, sem prejuízo do tempo destinado aos seus estudos e trabalhos de pesquisa.

15) Aconselha-se que a pós-graduação se faça em regime de tempo integral, pelo menos no que se refere à duração mínima dos cursos.

16) Os cursos de pós-graduação devem ser aprovados pelo Conselho Federal de Educação para que seus diplomas sejam registrados no Ministério da Educação e possam produzir efeitos legais. Para isso o Conselho baixará normas fixando os critérios de aprovação dos cursos.

(aa.) A. Almeida Júnior, Presidente da Comissão de Educação Superior; Newton Sucupira, relator; Clóvis Salgado, José Barreto Filho, Maurício Rocha e Silva, Durmeval Trigueiro, Alceu Amoroso Lima, Anísio Teixeira, Valnir Chagas e Rubens Maciel. 